Utah State University

DigitalCommons@USU

Library Faculty \& Staff Publications

Libraries

$1-23-2019$

\title{
Informing Website Navigation Design with Team-Based Card Sorting
}

Bret Crane

Utah State University

Teagan Eastman

Utah State University

Follow this and additional works at: https://digitalcommons.usu.edu/lib_pubs

Part of the Library and Information Science Commons

\section{Recommended Citation}

Alex Sundt \& Teagan Eastman (2019): Informing Website Navigation Design with Team-Based Card Sorting, Journal of Web Librarianship, DOI: 10.1080/19322909.2018.1544873

This Article is brought to you for free and open access by the Libraries at DigitalCommons@USU. It has been accepted for inclusion in Library Faculty \& Staff Publications by an authorized administrator of DigitalCommons@USU. For more information, please contact digitalcommons@usu.edu.

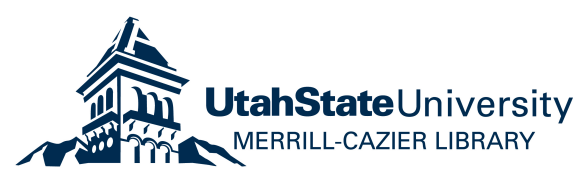


Title:

Informing Website Navigation Design with Team-Based Card Sorting

\section{Authors}

Alex Sundt

Web Services Librarian

Utah State University Libraries

Alex.sundt@usu.edu

Teagan Eastman

Online Learning Librarian

Utah State University Libraries

Teagan.eastman@usu.edu 


\begin{abstract}
In 2016, Utah State University (USU) Libraries redesigned the library website's main menu and underlying information architecture (IA) in response to a number of known usability problems and limitations. Card sorting studies were conducted with a group of USU undergraduate students and a mixed group of faculty and graduate students to help develop a better understanding of users' mental models of library-related research and service tasks. Participants worked in teams to sort, rank and label cards pertaining to the content and feature of the library's website. Afterwards, participants discussed and performed usability tasks on each other's categories. Results were used to inform the design of a new IA and menu structure, while best practices from usability studies and trends in academic library website design were used to help with menu and link labeling. The final design was validated through follow-up discussions with staff, usability tests, and category/reverse category tests.
\end{abstract}

\title{
Keywords
}

Card Sorting, User Studies, Academic Libraries, Information Architecture, Mental Models 


\section{Introduction}

Academic library websites are often referred to as the "virtual public face" or "front door" of the library (Keck, 2001, 127; McGillis \& Toms, 2001, 355). While these analogies certainly capture the prime importance of the website, they don't really do justice to experiences of the users who must navigate our virtual spaces. A more accurate analogy might be the building itself, with its separate wings and floors representing different collections and service points, except without the advantage of visual cues available to most in-person users. Without these benefits, online users must depend solely on hyperlinks to find their way around the library website, with the main menu serving as map of the overall structure. Links, therefore, not only need to be labeled in ways that users can easily understand, they must also be organized within a system that's meaningful to them, and ideally, which follows their own mental model of what a library website should be.

Given the critical role labeling and information architecture play in navigation, in 2016, Utah State University (USU) Libraries decided to conduct card sorting tests in order to incorporate a better understanding of the mental models users employ when approaching academic research and online library environments. This represented a major step in the Libraries' ongoing efforts to redesign the website, which since 2014 had been making continuous improvements, mostly focused around visual design and addressing known usability and content problems page by page. By focusing our attention on the information architecture as a whole, including the design of a global menu and labeling across the website, not only would major usability problems be corrected, but the website would have a stronger, more user-centered foundation, leading to more long-term user experience gains. 


\section{What is Card Sorting?}

Card sorting is a simple user research method in which content or features of a website are written on index cards and given to users to sort into related groups and categorize, helping to illustrate how users associate different concepts within an information space. Comparing different users' group and categorize cards can help identify trends in how users approach website tasks, information that is useful for designing more user-friendly website hierarchies and navigation systems. In addition to this quantitative data, qualitative data gathered by observing and eliciting feedback from participants is perhaps more useful, as it provides context for understanding users’ grouping decisions (Brucker, 2010, 52; Nielsen, 2004).

Open sorting, in which users create their own categories, and closed sorting, where users are given pre-defined categories, are the most common card sorting methods. Rosenfield and Morville (2002) recommend using open sorting for exploring users' information behaviors and mental models, and closed sorting to help validate menu structures and labels for more finalized or current designs. In addition, participants are often allowed to discard, re-label, or duplicate cards to place under multiple categories - all data points that provide additional insight into how they appropriate information space. These basic methods can be customized in different ways to fit different needs or design goals. For example, the modified-Delphi approach provides a method where a structure is created through open sorting, then refined independently by participants through several rounds, limiting the impact of peer influence, while producing a more refined structure in a shorter timeline (Paul, 2008). 


\section{Card Sorting in Academic Libraries}

Many academic libraries have used card sorting to inform the design of library websites, including an earlier project at USU (Duncan \& Holliday, 2008). Card sorting projects are typically employed at the early stages of a redesign process with the goal of shifting from a library-focused to a more user-focused approach to design (Dickstein \& Mills, 2000; Ebenezer, 2003; Kitalong, Hoeppner, \& Scharf, 2008). Uncovering trends in how users sort content can help libraries organize their websites around users' mental models of a library. For example, Faiks and Hyland (2000), used cluster analysis to identify where users had high levels of agreement regarding card groupings, providing Cornell University Library with a more usercentered starting point for their menu redesign. Low-agreement cards are also of interest, as they indicate where users might be confused by technical terms, or simply don't know how content should be grouped alongside other main categories (McHale, 2008, 154).

Card sorting is not without its limitations. More often than not, card sorting data is messy and difficult to analyze, so results of card sorting studies should be taken with a grain of salt, especially when designing for a wide range of audiences (Brucker, 2010, 43). While providing a good starting point for user-centered design, librarians also need to be aware of their own biases and avoid the interpreting results from a "librarian knows best" mentality (Dickstein \& Mills, 2000). For these reasons, librarians should strive for a balance between the needs of different user groups and their own perspectives and expertise (Brucker, 2010, 52; Faiks \& Hyland, 2000). Additionally, cards labels need to be easy for participants to understand quickly and out of their natural context (Spencer, 2004). Because library terms can be especially confusing, Brucker $(2010,51)$ recommended adding a simple description on the back of cards to help study 
facilitators know how to explain the concept to participants. Labels should also be carefully crafted to avoid biasing participants, for example by using keywords that may imply patterns and influence participants' grouping decisions (Faiks \& Hyland, 2000). To limit this kind of keyword-matching, Nielsen (2009) recommended using synonyms and non-parallel sentence structures.

Card sorting should ideally be used along with other user research techniques, such as usability testing, in order to validate user-generated categories and groupings against realistic scenarios. For example, MIT Libraries used a post-sorting category test, in which users list items they would expect to find under a given category, and a reverse category, in which users are asked to select a category label in response to a task-based scenario (Hennig, 2001). Later studies have adopted a similar multi-step approach for validating categories developed through card sorting (Duncan \& Holliday, 2008; Hepburn \& Lewis, 2008; Whang, 2008), while others have incorporated card sorting as one part of a broader user research and redesign process (Hepburn \& Lewis, 2008; Robbins, Esposito, Kretz \& Aloi, 2007; Turnbow, Kasianovitz, Snyder, Gilbert, \& Yamamoto. 2005; Ward, 2006). The benefits and downsides of using online, remote card sorting tools have also been explored. Online testing tools make it easy to deploy tests and potentially reach a wider audience of users, including students and library users at a distance. In addition, these applications also provide features that can make data analysis much easier compared to paper-based sorting. However, technical issues and the limitations of online interfaces can introduce problems for users, and more critically, are likely to miss much of the observational and other qualitative data that cannot be gathered remotely (Ford, 2013; Paladino, Klentzin, \& Mills, 2017). 


\section{History of Information Architecture at USU}

As part of an earlier redesign of the USU library website, Duncan and Holliday (2008) described a detailed card sorting process that started by first developing a comprehensive set of website requirements derived from a user survey, a review of reference transactions, and interviews with staff. Requirements that emerged were prioritized as "Absolutes," "Recommended," and "Extras", and then sorted into four categories: "Collection Access," "Services," "Information About the Library," and "Help Using the Library." For example, absolute requirements under "Collection Access" included links to the catalog and databases, while links to style manuals and other web resources were listed as "Recommended." Cards were derived based on highly-rated requirements, which were then tested with library users, and validated using task-based testing and feedback from library staff. This work provided a deep understanding of library users and lead to a new website grounded in user-centered design principles, which was launched in 2006. However, after several years of adding content and updating the interface and visual design, by 2012, most global navigation links had been relegated to the footer area of the page, what library staff commonly referred to as the "trashcan." In its place was a left-hand "Quicklinks" menu for some service and help links and a horizontal main menu with just five links to popular destinations like the library's e-resources list and study rooms.

By 2016, some organization remained intact, but most of the libraries' services and resources were not presented in any systematic, globally-navigable way. While the curated design of our main menu allowed for quick access to several key features, the lack of global navigation effectively hid the full scope of resources and services available to users. This was especially 
problematic for users who entered the site from a subpage, as there was no easy way to navigate to many important pages without first returning to the homepage. Aside from homepage links, user testing confirmed that most library users could not find important content.

\section{Research Goals}

Clearly, new navigation systems were needed for the website, and it was decided that starting with a fresh information architecture would ensure that newer services and content, as well as new approaches and expectations for websites among library users, would be reflected. For instance, Duncan and Holliday's (2008) card sorting project was conducted in 2003, well before smartphones became ubiquitous and mobile-optimized websites set an expectation for new, mobile use cases for the web. As an example, movie-goers may now be just as likely to purchase tickets on their way to a movie, rather than waiting in line. Given that mobile has had a significant impact on users' online behavior, it seemed reasonable to the study team to assume that users' mental models for library and online research have undergone similar changes. While we had a good idea of how an effective global navigation menu could be designed, we were wary of making assumptions about our users' preferences and reverting to a "librarian-knows-best" mindset. A new card sorting study would help us get a sense of changes in the user landscape and guide the redesign process along a user-centered path.

The study team was also concerned with the terminology used across the website and what labels would be most effective for our categories and menu links. While labels were tested as part of Duncan and Holliday's (2008) study, as the website grew and evolved, the taxonomy they developed was not used consistently. Re-evaluating important link and user interface labels with 
an eye toward developing standardized vocabulary would be critical for the long-term sustainability of a new navigation system. Although terminology is a common focus of card sorting studies (Brucker, 2010; Hepburn \& Lewis, 2008; Robbins, Esposito, Kretz \& Aloi, 2007;), the lack of real-life context makes card sorting an imperfect tool for refining website labels (Rosenfeld \& Morville, 2002, 103). Instead, separate label testing and usability tests are ideal for refining important link and user interface labels. With this in mind, we decided to draw from best practices based on Kupersmith's (2012) analysis of library usability studies to refine menu and link labels. Additionally, in keeping with our continuous design methodology, we opted to do targeted tests after the menu was redesigned rather than systematic testing prior to launch.

\section{Methodology}

We conducted open sorting tests with groups of participants organized into several teams, a method that would make it easier for users to sort a large number of cards within a shorter period of time (Spencer, 2004). Group sorting also provided a unique opportunity for us to incorporate peer evaluation and task-based tests within the same exercise.

\section{Card Development}

The study team began by identifying website content and features to use for our cards. The set of requirements developed by Duncan and Holliday $(2008,303)$ was useful at this stage, as most items were still reflective of content on the current site. Along with a few more recent and anticipated items, we created a list of around 90 items to represent an exhaustive account of the content and feature needs of the library's current web presence. The study team met several 
times to narrow this list to a more manageable set of 38 key items to use for the tests. The final items were selected to represent all key areas of library services, including print and electronic collections and research tools, important services like interlibrary loan and course reserves, and information like library hours. The final items also included content that the team was unsure how to organize, such as suggestion forms and services for regional campus users, which would benefit from user input. Once the list was narrowed, clear and descriptive labels for the cards were written, along with brief descriptions to be placed on the back of each card for additional clarification. With the help of a student worker, the card labels and descriptions were carefully affixed to the front and back of individual Post-it Notes to ensure each note wasn't ripped from the stack. This would allow sorting exercises to be conducted on white-board walls in one of the library's open classrooms. Several stacks of various colors were made so that each team could be color-coded. Additional cards were included later in the testing process for specific tests with faculty members and graduate students, bringing the total to 45 (see Appendix A).

\section{Population}

The tests were organized and conducted in two separate rounds, one with undergraduate students, and the second with a mix of graduate students and faculty members. Prior to the formal tests, a trial exercise was conducted with library student workers to help refine the testing process. Although these students had more in-depth library experience, we decided to include this data in our final analysis because we felt it fell within the normal range exhibited by many undergraduates. For the regular tests, participants were recruited using the promotional carousel on the library website and through targeted emails to department faculty inviting them to participate. Nielsen (2004) recommends testing with at least 15 users to generate enough data for 
a valid result. While 15 undergraduate users participated in the first round of tests, including four library student workers who participated in the trial exercise, only five faculty members and six graduate students participated in the second round. While this does not invalidate the results of the exercises they participated in, more data is necessary to get a fuller picture regarding the needs and priorities of these groups. In this case, we plan to conduct additional research specifically with graduate students and faculty members, perhaps using other participatory design activities or in-depth interviews, to validate that the new menu accurate captures their needs.

Each formal test lasted approximately 90-minutes and took place in one of the library's openplan classrooms. Participants were divided into three "teams" of 3-5 participants. In order to reduce inter-group bias, undergraduate participants were randomly assigned to a team as they entered the room. Faculty and graduate students were grouped into two faculty teams, and one team of graduate students. However, because one graduate student arrived late to the testing, and the number of faculty members was lower than expected, one of the faculty teams ended up being a mix of two faculty and one graduate student, which may have influenced the results from this team. See Table 1 for the composition of each team.

<Insert Table 1>

\section{Testing Process}

To begin, a facilitator explained the purpose of the exercise, the procedures for the activity, and provided informed consent information to participants. Next, each team was provided with a stack of cards, a pen, a blank set of Post-it notes, and a large whiteboard and dry erase markers. 
Participants were asked to read and stick each Post-It note on the board, then start sorting them into groups. Participants could use blank notes to create duplicate cards and create a miscellaneous category for cards that they were not sure where to place. To ensure participants stayed on track, a facilitator was available to answer questions or clarify cards that participants found confusing. However, based on recommendations from Faiks and Hyland (2000), we kept our explanations fairly abstract and avoided referencing the current website.

During the sorting activity, participants were encouraged to discuss amongst themselves and use the "think-aloud" method to help facilitators get insight into their thought process, which facilitators documented. After coming to a consensus about the categorical grouping of their cards, participants were asked to arrange the cards from top to bottom in order of most to least important, and provide a brief, user-friendly label for each category. Next, facilitators posed questions to get more information about each team's decision-making, which were documented in written notes and annotations on the whiteboards or cards themselves. Post-sorting questions included:

- How did you come up with these groups and group names?

- Were there any items your team debated? If so, why did you disagree on these items?

- Which items do you use most or are most important for you?

Separate questions were used for the second round of testing. Faculty participants were asked "Which items do you think are most important for your students to use?" Graduate students were asked "Which items do you think are most important for your fellow students to know about?" In addition to notations in response to specific facilitator questions, participants also independently 
added their own rich annotations, in some cases even drawing boxes around cards or sketching homepage layouts and describing features in the margins of their boards, providing additional levels of organization to the boards, and yet more qualitative information for us to analyze (Figure 1).

<Insert Figure 1>

Next, each team of participants were asked to review each other's boards. Large sheets of paper were placed over the cards, leaving only the category labels exposed. Teams then rotated around the room and conducted a reverse category test in which they were asked to select the category they were most likely to look under to find several items. This helped expose problems with each team's labels and card organization. For the first round, undergraduate students were asked to complete tasks as they rotated to each board (See Table 2). For the second round, the test was administered using a worksheet for each participant, a change that was made primarily to improve the flow of the activity. Additionally, the different questions were used in the second round to reflect services and needs geared more toward advanced users (Table 3).

$<$ Insert Table 2>

<Insert Table 3>

The final exercise of the card sorting activity was a large group discussion about the merits of different card groupings and labels. Facilitators posed a few final questions to spur discussion (Table 4). After asking for any final feedback or questions, participants were thanked for their time and their card sorting boards were photographed and later recorded in a spreadsheet. Finally, facilitators met after each test to debrief and discuss outstanding observations. <insert Table 4> 


\section{Design Validation}

After conducting the card sorting tests, a new architecture and menu design was launched for the website to coincide with the start of the fall semester 2017. This allowed us to immediately put the new menu into action, rather than waiting to do additional user testing and launching between semesters. In keeping with our continuous design approach, we followed up with several rounds of quick usability tests to ensure key services were still findable using the new menu, and both category and reverse category tests using the methods described by Hennig (2000).

\section{Results}

Navigation structures developed by participants ranged from deep to very shallow and featured between 4-9 main categories. Three teams (D, E, and G) created 3-4 subcategories, usually falling under main categories related to help or library resources and collections. In many cases, divisions within or between categories matched our expectations. For example, several teams created distinct sections for digitized and archival collections. Some groupings were less obvious. For example, teams D, E, and G created separate categories or subcategories for help content, distinguishing general help information from more in-depth services like consultations. One undergraduate explained this difference by saying "help is 'how do I use the library,' while services are more like 'I need help with my specific research project."' Finally, for both rounds of formal testing, multiple teams created categories or subcategories for content geared specifically for regional campus and online users. Only one group, team G, suggested audiencespecific subcategories, which they placed under a main category labeled "Educational Resources" that encompasses student-oriented services like study rooms, as well as faculty services like library instruction. Finally, several small outlier or miscellaneous categories were 
created for things like the university press (which is housed in the library), the library's account login, and library news and events.

\section{Card Rankings}

Once participants were finished sorting, they were asked to arrange the lists of cards from most to least important, which would help the study team gauge the priority users placed on different content and features. However, because physical card sorting is naturally messy, and some categories included many more cards than others, it was difficult to determine how each card was ranked within the overall organization. For the purposes of our analysis, we considered a card highly ranked if it appeared within the top 2-3 spots under any category or was otherwise marked by participants. Undergraduates frequently ranked the library catalog, e-journals, study rooms, chat, and FAQs as high-priority. Faculty and graduate students also ranked the catalog and ejournals highly, along with the e-resources list, course reserves, librarian consultations, and information like building hours and help for off-campus users. Teams B and F also used the whiteboard markers to add content they felt should be linked directly from the homepage (Figures 2, 3). Along with promotional content like library news, other content frequently placed on the homepage included research tools like the catalog and e-resources list, help services such as chat and our consultation system, building hours and contact information, and popular services such as our study rooms and ILLiad. Regardless of their background or level of expertise as researchers, users tended to have a fairly limited understanding of the wide variety of library services available and mainly honed in on a few key services and collections with which they were familiar. 


\section{Card Placement Trends}

After reviewing participants' suggested categories and card rankings, we focused on identifying major patterns in the placement of cards, clustering cards that were commonly placed together using the "eyeballing" method described by Nielsen (1994). To begin our analysis, the study team reviewed and normalized participants' category labels. Because Team F did not label their card groups, they were excluded from this analysis. This was, for the most part, a simple process of combining synonymous or similar labels. When a label was unclear, the study team looked at cards within the category, or drew insight from observations and discussions with participants, to decide how to normalize it. Four main categories were apparent after reviewing the data: "Materials," "Services," "Help," and "About." In some cases, teams used labels that spanned across the concepts of services, help, and general library information, for example the category “General Information and Help," suggesting these cards could be placed in multiple areas depending on the context. As a result, many of these items were mapped to multiple normalized categories.

After category labels were normalized, trends in the grouping of cards emerged. Among the 45 cards included in the exercises, 31 were high-agreement, meaning a majority of teams sorted them under a similar category. This reflects a significant improvement in agreement compared to Duncan and Holliday's (2008) open sort, where only six of the 52 cards they tested were in high agreement, with no cards being placed in the same category by all test participants. Of the six teams we included in our analysis, all placed popular tools like the library catalog, e-resources list, and specialized local collections within some type of "Materials" category. Not surprisingly, five of the six groups also placed tutorials for finding books alongside other library resources, 
while other tutorials, Ask a Librarian, FAQs, and other helpful information were frequently placed within a "Help" category. Finally, there was a high level of agreement among all six teams regarding the placement of library hours, staff contact information, floor maps, and other "About" information. While not totally unexpected, interlibrary loan was placed under a resource-related category by five teams, with only one team placing it under a services-related category. Similarly, course reserves was placed by all six teams alongside library resources like the catalog. (Table 5)

<insert Table 5>

Other service-type information, such as borrowing policies, the request form for acquisitions, and tutorials related to the research process were commonly placed in multiple categories spanning resource-, service-, and help-related categories. Content for regional campus and online users was typically placed in multiple areas, with $3 / 6$ placing this content under a help-related category. Similarly, the request/contact form for librarian consultations was placed under several categories, again with $3 / 6$ placing it under services. Finally, while most teams placed wireless and computer information under a help category, several duplicates were created and spread across multiple categories.

\section{Group Testing and Discussion}

Results of task-based tests helped to expose some problematic category labels and card arrangements, in particular the vagueness of labels like "resources," which several teams used for facility-based resources like study rooms. Group discussions with all teams generally revolved around the pros and cons of different organizational schemas and balancing the needs of different users. While participants seemed to generally agree that fewer main categories would 
be ideal, they also indicated a desire for more granular subcategories across help information and services.

While some undergraduates in our large group discussion liked having research resources categorized separate by print and electronic, many recognized the need for an overarching category to reduce user confusion. Faculty and graduate students also debated the pros and cons of shallow versus deep navigation structures, but in group discussion, most indicated a desire for a relatively deep information architecture with no more than five main categories.

Unsurprisingly, faculty and graduate students specifically mentioned that e-resources and interlibrary loan services should be easily accessible from the homepage. These participants also discussed jargon terms such as "digital scholarship" and "OER" as creating potential barriers for users.

\section{Menu Design and Validation}

After interpreting feedback from participants, the study team went about designing a new information architecture and global menu for the website based in part on trends in card groupings. As many have noted, designing a website that provides the ideal experience for the wide range of library users and their unique needs requires a difficult balancing act (Dougan \& Fulton, 2009; Duncan \& Holliday, 2008; Liu, 2008) Similarly, card sorting results won’t necessarily point to an ideal architecture and are better suited for getting a glimpse into users' mental models of an information space (Spencer, 2004). With this in mind, card sorting data was used alongside our knowledge as content experts with the goal of developing a flexible 
architecture that could accurately represent all the resources and services the library provides, while still being usable for a range of key audiences and use cases.

Drawing from high-agreement cards among participants, four normalized categories were apparent, and were giving the following labels:

- Find for library resources and research tools like the catalog.

- Services for services like interlibrary loan and facilities like study rooms.

- Help for all research and general help information and services.

- About for information such as building hours and the staff directory.

By providing a narrow and deep architecture, the design team felt these four categories were effective in representing the range of content currently on the website, while allowing room to expand as new content and features were added in the future. We also wanted to keep the number of categories small based on comments from participants that indicated a preference for limited menu choices with more inclusive categories. Category labels, selected to reflect natural language target terms based on recommendations from Kupersmith (2012), not only reflect trends among other academic libraries (Comeaux, 2017, 7), but in most cases were also evident throughout participants' models. One obvious exception is the use of "Find" instead of "Resources" or "Materials," terms that occurred in several teams' information structures. In this case, we opted for the more task-oriented term "Find" because it was popular in Comeaux's analysis (2017) and recommended by Kupersmith (2012). We also felt it would be more inclusive of both print and electronic collections, as well as research tools like the catalog and discovery layer. 
Secondary organization within these categories was based partly on card sorting results. For example, a subcategory for the library's special and digital collections was evident in several models suggested by participants. Similarly, two subcategories under the "Services" menu were created based on models that separated content specific to instructor and researcher audiences. In other cases, we deviated significantly from participant's suggestions. For example, two teams created separate categories for electronic and print resources, a distinction that would be problematic for presenting search tools like the catalog. Based on comments and observations during sorting, undergraduate participants appeared to be confused regarding the scope of collections included in the catalog and discovery layer, which may explain why this distinction emerged. Despite this, participants seemed to recognize during post-sort activities and discussions that separate categories might not be ideal for meeting a broad range of user needs.

Similar division was seen in some teams' help categories, which were separated based on two distinct purposes for seeking help: 1) general questions about using the library (such as navigating the stacks or using equipment), and 2) in-depth help with the research process, which was commonly associated with a service-type category. Like many libraries, Utah State University Libraries' website features various tutorials, FAQs, and user instruction and support content. Given that this variety was also reflected in the cards participants were given, this distinction among help categories makes sense. However, we were skeptical of how effective such a model would be in practice. For one, separate help categories labeled "Help with the Research Process" and "Help with Using the Library" were designed in Duncan and Holliday's $(2008,312)$ study, but were re-combined after user testing found that users were not sure when to 
use one category over the other. We were similarly concerned that users might not be able to distinguish between similar help categories and were reluctant to add additional choices or otherwise deter users from seeking help. It was also decided that given the scope of help features on the website, a more in-depth evaluation and redesign of the content was warranted prior to making any decisions regarding how they would be presented on the website. In the meantime, a single help category would avoid confusing users with too many similar choices.

In placing content into these categories, we generally followed high-agreement among test participants. One major exception was the portal for interlibrary loan and document delivery services, which five out of six teams placed under a materials-related category. This illustrates a tension between how librarians and online users define library content. While librarians would typically categorize this as a service, this finding supports observations that users don't always make the same distinctions between a library resource and library service (Paladino, Klentzin, \& Mills, 2017, 41), especially regarding material focused services like interlibrary loan (Duncan \& Holliday, 2008, 312). Based on this finding, we wanted to do additional testing to determine where users would look for interlibrary loan and other key services given more realistic scenarios.

Low-agreement cards were also of interest, as they suggest where content might benefit from being cross-referenced in multiple areas of the website. Cross-referencing is a design strategy recommended by Kupersmith (2012) but which Hulsberg and Monson (2011, 371) cautioned against, warning that too much redundancy could confuse users and limit their ability to find a clear path to meeting a particular need. Alternately, low-agreement could indicate where users 
commonly get confused or simply deviate in their approaches to completing website tasks. Given that there was low agreement among many cards related to library services and help information, the potential to subdivide or separate these categories remains a key question for future investigation and design work.

Finally, link labels were informed both by participant data and best practices from the usability literature. We specifically avoided the use of jargon and confusing terms, such as "catalog" or "resources," instead opting for more natural, target-oriented language such as "books and media" and "find." Once an architecture and labels were designed, a high-fidelity mockup featuring a drop-list "mega menu" was created to demonstrate how a new global navigation system might be implemented. It is was important for us to validate our interpretation of users' feedback, due to users' generally narrow understanding of library services and the potential for bias in our interpretations as librarian-designers. We therefore assessed the design against the knowledge and specific service expertise of all library staff. For two weeks, a large print-out of the mockup was posted in the library's breakroom, as well as sent out to all library staff via a Qualtrics survey for feedback (Figure 4). While the organization mostly received positive feedback, staff drew attention to several labeling issues, noting the potential for confusion around labels like "Get Involved" for gifts and donor information, and "Materials for My Class" for course reserves, which several study participants had suggested would be more understandable to undergraduate users. Based on staff feedback, we changed "Get Involved" to "Support USU Library," and decided to conduct usability tests to refine the label for course reserves. Staff also suggested that we add links for the writing center and other services that are housed in the library but not official library services. After reviewing staff feedback and making adjustments or plans 
for further study, we presented a final design to library department heads and administration for approval.

<insert Figure 4>

\section{Menu Validation}

Although task-based scenarios were included during the sorting exercises, these were mostly used to uncover problems with participants' raw affinity maps. Additional tests were needed to evaluate the menu structure we developed. In particular, we were concerned with potential vagueness with the label "Services," given that cards within this category were often sorted into multiple categories, and that this label was found to be problematic in Duncan and Holliday's $(2008,312)$ study. Would users understand this label and know to look for important features like the study room booking system under "Services," and not "Find"?

To answer these questions, usability tests and category and reverse category tests were conducted with undergraduate students during the spring semester of 2018. In our category test, users were able to successfully anticipate the kind of content they would be able to find under each category. Reverse category tests showed that while some users thought study rooms might be under a "Find" menu, the majority associated this item with the "Service" category. However, interlibrary loan and course reserves, two other important services, were both split between "Find" and "Services," with an equal number of students placing it within either category. Based on these results, it was decided that strategically placing related links within multiple categories would be the most effective solution. In the future, alternate labels or breaking the "Services" 
category into more context-specific subcategories, perhaps grouped by task, could provide a way to move away from this and other vague, catch-all labels.

In addition, follow-up usability tests uncovered problems with the placement and labelling of a few links. Overall, the new menu performed well, with users being able to successfully complete tasks using the categories and organization we had designed. Other plans for improvement, such as adding short descriptions for each link on all intermediate menu pages, are being explored to help contextualize menu content and increase usability of the menu. Moving forward, continuous testing and refinement will ensure the menu is both usable and able to grow as new features and content are needed.

\section{Discussion}

Our in-person approach of using open sorting methods produced rich, qualitative data from library users. While this made analysis difficult and time consuming, conducting the exercises in person, rather than using a remote testing program, made the tests more participatory and likely more engaging for participants. Combined with our team-based approach, the study provided a tactile, "in the trenches" perspective that allowed us to observe discussions and get a deeper understanding of users' thought processes as they grouped and prioritized different items. While all this data didn't necessarily override our intuition as librarians and web designers, it provided a useful check on our assumptions and ensured users were considered at every stage of the design process. Low-agreement content in particular helped to identify areas for future study and design work. 
One interesting area of low agreement was the bifurcation of collections into separate print and online categories. While this result may have been biased by the card language, the fact that this distinction emerged from a broad set of cards suggests that electronic access (or lack thereof) is an important decision-making factor for at least some students. Therefore, for some it may make sense to model the academic library as two distinct collections, a paradigm that contrasts sharply with the kind of one-stop, cross-silo searching emphasized on most library homepages.

Additionally, comments and observations from participants during the sorting process indicated that some students may be confused about the scope of library collections and search tools like the discovery layer.

We also observed that users, regardless of their background or level of expertise as researchers, exhibited a narrow focus on a few familiar services and collections, and generally lacked a broad understanding of all that the library offers. This underscores problems with a "one-size-fits-all" approach and strengthens the case for greater personalization of the library user experience (Liu, 2008). Audience-based menus are one popular approach libraries employ to tailor the website to different user groups. However, these can introduce potential problems, such as overwhelming users with choices and adding extra steps for them to complete tasks (Sherwin, 2015), while providing only a shallow form of personalization, usually based around the shared needs of broad user groups. In contrast, deeper levels of customization, such as personalized landing pages, the ability to select "favorite" resources, and other features common to services like Google, remain underexplored in libraries (Comeaux, 2017).

\section{Limitations}


While card sorting ultimately helped us understand more about library users' mental models, there were some limitations to our approach. First, while 15 undergraduates were tested in the first round of card sorting, we did not reach the recommended number of participants for either graduate students or faculty members (Nielsen, 2004). Knowing that different user groups have different approaches and needs, including more from each of our key communities would have strengthened the results. In the same vein, mixing graduate students and faculty participants in the same session may have also limited our ability to glean insights specific to each user group.

Second, while there were many advantages to grouping participants into teams, the results are subject to the same limitations of other focus-group-style research, namely the results may have been skewed by a "groupthink" atmosphere. Similarly, while card labels and descriptions were written carefully and the risk of keyword-matching was likely reduced due to the open nature of the card sort, we cannot be sure that some language we used did not influence participants' sorting decisions. Indeed, some of our label choices, such as "Book Catalog," which may imply the catalog is a print-oriented tool, may explain why two separate groups created distinct categories for print and online resources.

A specific goal of this project was to shift away from a librarian mindset, but card sorting produces raw data and often reflects library users' narrower interests. Compromises must naturally be made between the vision of test participants and the complicated realities of library collections and technology. Users' suggestions must therefore be mediated by the expertise of librarians and the library-designer, which might undermine the benefits of participatory design. We may indeed have done this in some cases, for example the category label "Find," which 
draws on librarian best practices, but deviates significantly from our users' suggested term "Materials." Based on results from reverse card sorting and usability testing, our users seemed to be confused about what broader library resources - like computers and study spaces - might also be included under "Find." While "Materials" may not be ideal for describing electronic collections and broader search tools, it would avoid this ambiguity. A positive aspect of our project was that our continuous approach to testing and design provided opportunities to constantly reevaluate our assumptions and strike a better balance between users' expectations and our vision and goals as librarians.

\section{Conclusion and Next Steps}

The findings and observations from our card sorting exercises, together with trends in low agreement cards, illustrate some of the challenges libraries face from what Dempsey calls “network-level” web services (2007). Namely, libraries provide a plethora of resources and services, which are pulled together via the website to form a more or less integrated user experience. Yet many users will only take advantage of a small segment of what's available, and instead appear to pick and choose from a handful of familiar tools to fit their on-demand needs and individual goals. Not only is the library no longer the main starting point for research, the homepage-focused, one-size-fits-all model of library websites seems to be a poor complement to users' research lives at large (Schonfeld, 2015). While there are clear benefits and use cases for broad, integrative search systems, users may derive greater benefit from having greater personalization, such as more integrated user accounts and other features that would allow for a more tailored user experience. 
The results of our card sorting project provided our team with a useful starting point for the redesign of our website architecture, while also exposing some of the tensions between making things simple and intuitive (one definition of usability) and adequately representing complex collections and orienting users to them. As an inductive process that draws on user- and librarian-generated website requirements as the data points users are tasked with assembling, we feel fairly confident that our card sorting exercise captured an accurate picture of how many of our users conceptualize an academic library website. However, more information is needed to understand the broader context and external factors that influence academic information use. As a next step, ethnographic and other participatory techniques would provide deeper insight into the experiential lives of our users, helping us not just improve the library website, but revealing ways to expand our overall digital strategy to provide library services that meet users on their own terms.

\section{Acknowledgements}

The authors thank Erin Davis, Britt Fagerheim, Andrea Krebs and Robert Heaton for their assistance in the design and implementation of this study. We also thank Dustin Olson and Paul O'Donnell for their work in redesigning the USU Libraries' website menu, and Jennifer Duncan and Wendy Holliday for their earlier IA work and graciousness and guidance in supporting this project. 
Brucker, J. (2010). Playing with a bad deck: The caveats of card sorting as a web site redesign tool. Journal of Hospital Librarianship, 10(1), 41-53. https://doi.org/10.1080/15323260903458741

Comeaux, D. J. (2017). Web design trends in academic libraries - a longitudinal study. Journal of Web Librarianship, 11(1), 1-15. https://doi.org/10.1080/19322909.2016.1230031

Dempsey, L. (2007, March 3). Libraries, books and network level services. Retrieved from http://orweblog.oclc.org/libraries-books-and-network-level-services/

Dickstein, R., \& Mills, V. (2000) Usability testing at the University of Arizona Library: How to let the users in on the design. Information Technology \& Libraries, 19(3), 144-151.

Dougan, K., \& Fulton, C. (2009). Side by side: What a comparative usability study told us about a web site redesign. Journal of Web Librarianship, 3(3), 217-237. https://doi.org/10.1080/19322900903113407

Duncan, J., \& Holliday, W. (2009). The role of information architecture in designing a thirdgeneration library web site. College \& Research Libraries, 69(4), 301-318. https://doi.org/10.5860/crl.69.4.301

Faiks, A., \& Hyland, N. 2001. Gaining user insight: A case study illustrating the card sort technique. College \& Research Libraries, 61(4), 349-357. https://doi.org/10.5860/crl.61.4.349

Ford, E. (2013). Is digital better than analog? Considerations for online card sort studies. College and Research Libraries News, 74(5), 258-261.

Hennig, N. (2001). Card sorting usability tests of the MIT Libraries' web site: Categories from the user's point of view. Usability assessment of library-related web sites: Methods and case studies, 88-99. 
Hepburn, P., \& Lewis, K. M. (2008). What's in a name? Using card sorting to evaluate branding in an academic library's web site. College \& Research Libraries, 69(3), 242-250. https://doi.org/10.5860/crl.69.3.242

Keck, A. (2001). Opening the front door. Journal of Religious \& Theological Information, 3(34), 127-137. https://doi.org/10.1300/J112v03n03_09

Kitalong, K. S., Hoeppner, A., \& Scharf, M. (2008). Making sense of an academic library web site: Toward a more usable interface for university researchers. Journal of Web Librarianship, 2(2-3), 177-204.

Kupersmith, J. (2012). Library terms that users understand. Retrieved from https://escholarship.org/uc/item/3qq499w7

Liu, S. (2008). Engaging users: The future of academic library web sites. College \& Research Libraries, 62(4) 355-367. https://doi.org/10.5860/crl.69.1.6

McGillis, L., \& Toms, E. (2001). Usability of the academic library web site: Implications for design. College \& Research Libraries, 62(4), 355-367.

McHale, N. (2008). Toward a user-centered academic library home page. Journal of Web Librarianship, 2(2-3), 139-176. https://doi.org/10.1080/19322900802205825

Nielsen, J. (2003, June 30). Information foraging: Why Google makes people leave your site faster. Retrieved from https://www.nngroup.com/articles/information-scent/

Nielsen, J. (2004, July 2004). Card sorting: How many users to test. Retrieved from https://www.nngroup.com/articles/card-sorting-how-many-users-to-test/

Nielsen, J. (2009, August 24). Card sorting: Pushing users beyond terminology matches. Retrieved from https://www.nngroup.com/articles/card-sorting-terminology-matches/ 
Nielson, J. (1994, December 31). 1994 design of SunWeb: Sun Microsystems’ intranet.

Retrieved from https://www.nngroup.com/articles/1994-design-sunweb-sunmicrosystems-intranet/

Paladino, E. B., Klentzin, J. C. \& Mills, C. P. (2017). Card sorting in an online environment: Key to involving online-only student population in usability testing of an academic library web site. Journal of Library \& Information Services in Distance Learning, 11(1-2), 3749.

Paul, C. L. (2008). A modified Delphi approach to a new card sorting methodology. Journal of Usability Studies, 4(1), 7-30.

Robbins, L. P., Esposito, L., Kretz, C., \& Aloi, M. (2007). What a user wants: Redesigning a library's web site based on a card-sort analysis. Journal of Web Librarianship, 1(4), 327. https://doi.org/10.1080/19322900802111346

Rosenfeld, L., \& Morville, P. (2002). Information Architecture for the World Wide Web: Designing Large-Scale Web Sites (Second edition). Cambridge, Mass: O'Reilly Media.

Schonfeld, R. C. (2015, March 26). Meeting researchers where they start: Streamlining access to scholarly resources. Retrieved from https://sr.ithaka.org/blog/meeting-researchers-wherethey-start-streamlining-access-to-scholarly-resources/

Sherwin, K. (2015, September 7). Audience-based navigation: 5 reasons to avoid it. Retrieved from https://www.nngroup.com/articles/audience-based-navigation/

Spencer, D. (2004, April 7) Card sorting: A definitive guide. Retrieved from http://boxesandarrows.com/card-sorting-a-definitive-guide/

Turnbow, D., Kasianovitz, K., Snyder, L. Gilbert, D., \& Yamamoto, D. (2005). Usability testing for web redesign: A UCLA case study. OCLC Systems \& Services, 21(3), 226-234. 
Whang, M. (2008). Card-sorting usability tests of the WMU Libraries' web site. Journal of Web Librarianship, 2(2-3), $205-218$. 


\section{Appendix A}

\begin{tabular}{|c|c|}
\hline \multicolumn{2}{|c|}{ Card Labels and Descriptions Included in Sorting Exercises } \\
\hline Card Labels & Descriptions \\
\hline Search box & $\begin{array}{l}\text { Lets you do a search of all library books and some article } \\
\text { databases, but not all library content is included }\end{array}$ \\
\hline $\begin{array}{l}\text { Article databases / e- } \\
\text { resources }\end{array}$ & $\begin{array}{l}\text { Includes links to library databases covering many topics and } \\
\text { subject areas; types of information include scholarly articles, } \\
\text { newspapers, statistical, etc. }\end{array}$ \\
\hline Book catalog & Search for print and eBooks owned by the library \\
\hline eBooks & List of eBook platforms and eBook help guides \\
\hline Electronic journals list & $\begin{array}{l}\text { Search through all electronic journal titles the library subscribes } \\
\text { to }\end{array}$ \\
\hline $\begin{array}{l}\text { Special Collections \& } \\
\text { Archives }\end{array}$ & $\begin{array}{l}\text { Physical collection of rare books, photographs, manuscripts about } \\
\text { regional history, and USU historical information }\end{array}$ \\
\hline Digital Collections & $\begin{array}{l}\text { Digitized photographs and other items from Special Collections } \\
\& \text { Archives }\end{array}$ \\
\hline Digital Exhibits & Digitized materials from Special Collections and Archives \\
\hline DigitalCommons@USU & $\begin{array}{l}\text { Electronic copies of research articles and conference } \\
\text { presentations by USU faculty and students }\end{array}$ \\
\hline Course Reserves & $\begin{array}{l}\text { Textbooks and other materials available for short-term loan to } \\
\text { students in particular classes }\end{array}$ \\
\hline Interlibrary Loan & $\begin{array}{l}\text { You can request books, articles, and other materials from other } \\
\text { libraries if USU libraries doesn't have a copy. We will borrow it } \\
\text { for you. }\end{array}$ \\
\hline $\begin{array}{l}\text { Government Documents } \\
\text { [added Round 2] }\end{array}$ & $\begin{array}{l}\text { Information about the Government Documents section of the } \\
\text { Library, including how to search for government information }\end{array}$ \\
\hline Main Building Hours & Regular and holiday hours the library building is open \\
\hline $\begin{array}{l}\text { Address / general contact } \\
\text { phone / email }\end{array}$ & General contact information for the library \\
\hline Staff directory & Contac \\
\hline Floor maps & $\begin{array}{l}\text { Maps of the amenities on each floor of the library, including the } \\
\text { call numbers (how books are shelved), group study rooms, } \\
\text { bathrooms, etc. }\end{array}$ \\
\hline Visiting the Library & Driving directions and parking info for people visiting the library \\
\hline $\begin{array}{l}\text { Printing, Copying and } \\
\text { Scanning }\end{array}$ & $\begin{array}{l}\text { Locations of printers, copiers and scanners, how to use, pay for } \\
\text { prints, etc. }\end{array}$ \\
\hline Wireless and Computers & $\begin{array}{l}\text { Information for connecting to the wireless network, location and } \\
\text { software availability of library computers }\end{array}$ \\
\hline $\begin{array}{l}\text { Library Circulation / Use } \\
\text { Policies }\end{array}$ & $\begin{array}{l}\text { Procedures for using library materials, what items can be checked } \\
\text { out, for how long; other building use policies, etc. }\end{array}$ \\
\hline Library News \& Events & $\begin{array}{l}\text { Upcoming exhibits and events at the Library, and information } \\
\text { about featured library collections }\end{array}$ \\
\hline $\begin{array}{l}\text { Gift Information, Forms } \\
\text { and Policies }\end{array}$ & $\begin{array}{l}\text { Information about donating materials or making gifts to the } \\
\text { library }\end{array}$ \\
\hline
\end{tabular}




\begin{tabular}{|c|c|}
\hline $\begin{array}{l}\text { Regional Campus } \\
\text { Services }\end{array}$ & $\begin{array}{l}\text { General information about library resources and services } \\
\text { available for regional campus students, faculty, and staff }\end{array}$ \\
\hline Poster and Map Printing & $\begin{array}{l}\text { Information about getting topographical maps or conference } \\
\text { posters printed in the library }\end{array}$ \\
\hline $\begin{array}{l}\text { Study Room Booking } \\
\text { System }\end{array}$ & $\begin{array}{l}\text { Allows students to pick and reserve group study rooms in the } \\
\text { library }\end{array}$ \\
\hline $\begin{array}{l}\text { Access to Print Resources } \\
\text { (for regional campus } \\
\text { students) }\end{array}$ & $\begin{array}{l}\text { Information for students and faculty at the regional campuses for } \\
\text { getting print books sent to their home }\end{array}$ \\
\hline $\begin{array}{l}\text { Library Account / Online } \\
\text { Book Renewal }\end{array}$ & Library account for renewing books and paying fines online \\
\hline Book Suggestion Form & Suggest a book for the library to purchase \\
\hline Resource Problems Form & $\begin{array}{l}\text { A form to report and get assistance with problems accessing a } \\
\text { resource through the website or a library database }\end{array}$ \\
\hline $\begin{array}{l}\text { Streaming Media Request } \\
\text { Form }\end{array}$ & $\begin{array}{l}\text { Form to ask the library to get rights to stream a film or video to } \\
\text { allow a class to have digital access via Canvas }\end{array}$ \\
\hline $\begin{array}{l}\text { Open Educational } \\
\text { Resources (OER) [added } \\
\text { round 2] }\end{array}$ & $\begin{array}{l}\text { Free to use online textbooks and other educational materials; the } \\
\text { Library can help match resources to classroom needs }\end{array}$ \\
\hline $\begin{array}{l}\text { Research Data } \\
\text { Management [added } \\
\text { round 2] }\end{array}$ & $\begin{array}{l}\text { Help for creating data management plans, finding data } \\
\text { repositories, and fulfilling data management requirements of } \\
\text { grant-awarding agencies. }\end{array}$ \\
\hline $\begin{array}{l}\text { Theses and Dissertations } \\
\text { [added round 2] }\end{array}$ & $\begin{array}{l}\text { Information for submitting your thesis or dissertation for digital } \\
\text { preservation, and finding past T\&D by USU students. }\end{array}$ \\
\hline $\begin{array}{l}\text { Library Instruction } \\
\text { Program [added round 2] }\end{array}$ & $\begin{array}{l}\text { Information about including classroom instruction, online guides } \\
\text { and learning modules from USU librarians in your course. }\end{array}$ \\
\hline $\begin{array}{l}\text { USU Press [added round } \\
\text { 2] }\end{array}$ & $\begin{array}{l}\text { Information about the USU Press publications and upcoming } \\
\text { titles }\end{array}$ \\
\hline $\begin{array}{l}\text { Digital Scholarship } \\
\text { [added round 2] }\end{array}$ & $\begin{array}{l}\text { Information about copyright and open-access publishing options } \\
\text { for USU students and faculty }\end{array}$ \\
\hline Chat & $\begin{array}{l}\text { Chat button that allows you to get help from staff at the library } \\
\text { info desk }\end{array}$ \\
\hline Help Email and Phone & Email address and phone number for the library Info Desk \\
\hline $\begin{array}{l}\text { Request a Consultation } \\
\text { with a Librarian }\end{array}$ & $\begin{array}{l}\text { Request an online or in-person meeting with a librarian to get } \\
\text { help with a research question or project }\end{array}$ \\
\hline FAQs & $\begin{array}{l}\text { Frequently asked questions for using the library building and } \\
\text { resources }\end{array}$ \\
\hline Off-Campus Help Guides & $\begin{array}{l}\text { Instructions and help related to problems accessing library } \\
\text { databases and online resources outside of the campus wifi }\end{array}$ \\
\hline How to Find a Book & Step by step instructions for finding a book in the library \\
\hline How to Use the Library & $\begin{array}{l}\text { Basic information about how to use the library and what services } \\
\text { are available }\end{array}$ \\
\hline Research How-To's & Short help guides for doing research and navigating the library \\
\hline $\begin{array}{l}\text { Access } \\
\text { Problems/Troubleshooting }\end{array}$ & $\begin{array}{l}\text { Tips for solving problems with accessing electronic journals, } \\
\text { eBooks and other online resources from the library }\end{array}$ \\
\hline
\end{tabular}

